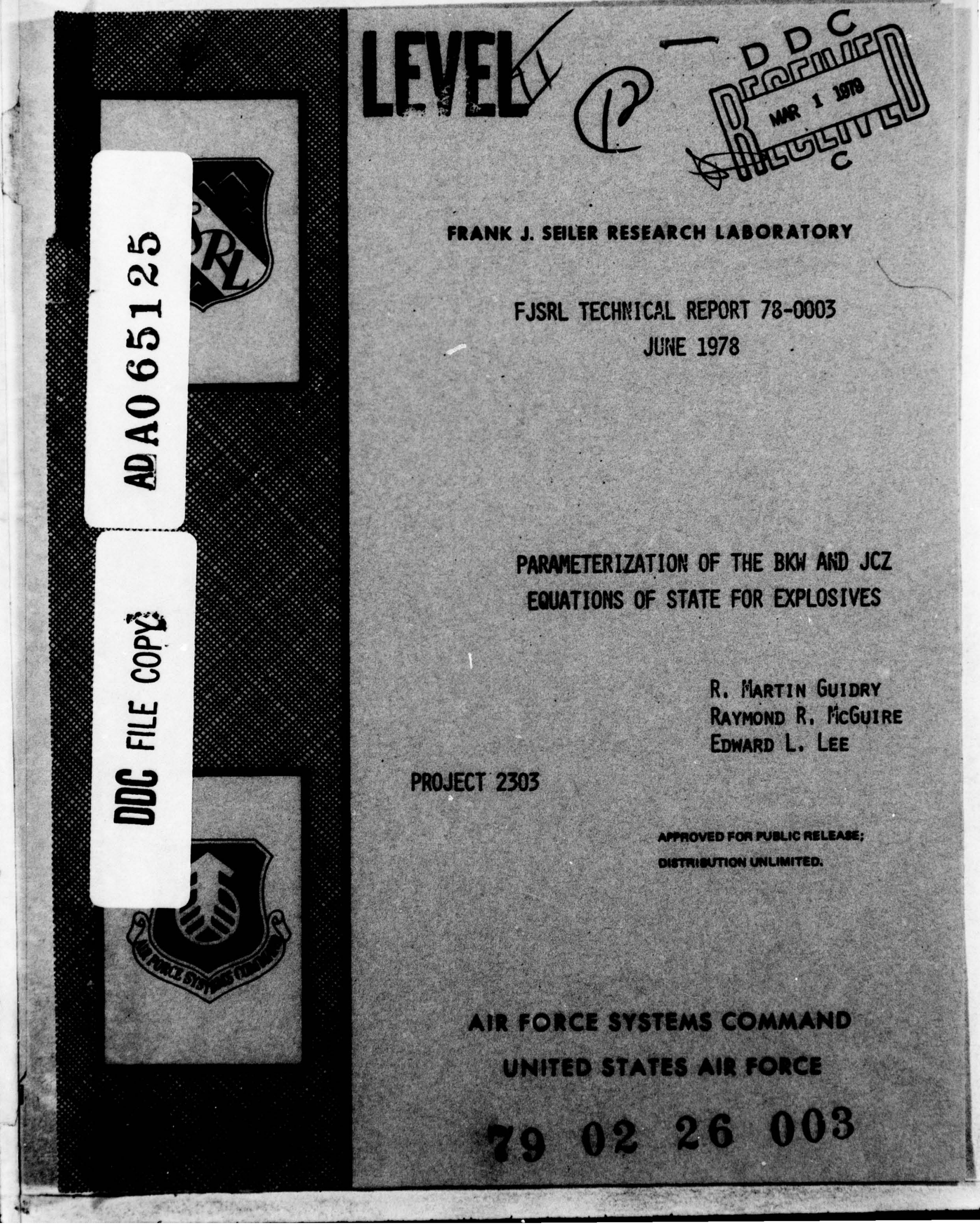




$$
p \mathrm{~s}=\mathrm{x}
$$

\section{Fusce- $-78-0003$}

Inis cocumint tas perpered by the Enengetic Materfals Division,

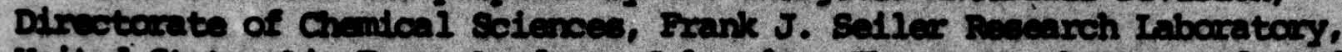

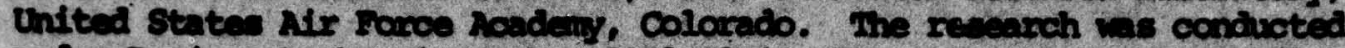
wher Project Work Unit Nuber 2303-73-04, Detonation Propenty Prediction and Hobling. Capt R. Inxtin Cuidey was the Froject selentist in charge of the wak.

When us coverment diratings, epeofifications or other data are used for any pugoce other than a dofinitely related Government procurement operation, the covernent thereby inclire no reoponaibillty nor any cbligation whatsoover, and the sect that the covecument may have formalated, furniphed or in any lay arpilied the caid draning, epeciffications or other data is not to

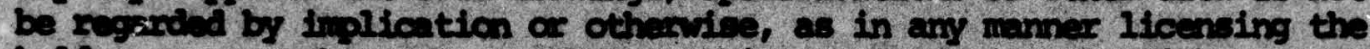
holex or any other perecen or congonration or conveyling ans Iflohts or paradeion to manudoture, ves or sall any patented invention that may in any way be rellated thereto.

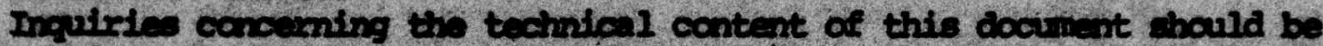

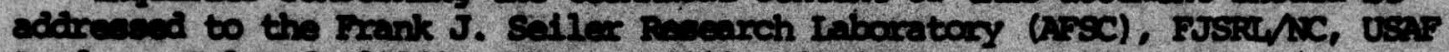

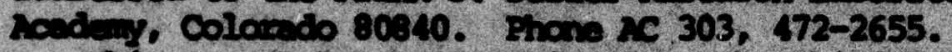

Ind repert has bon reviend by the chief soientiot and is releasable

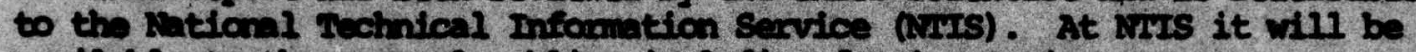

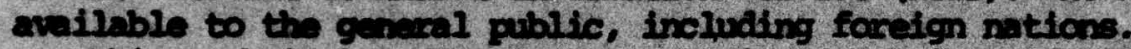

this toohical report hes ben revileded and is appeoved for publication.

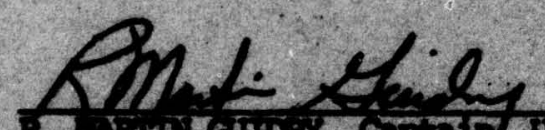

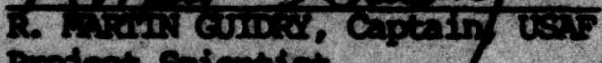
Feoflect Sedentibt

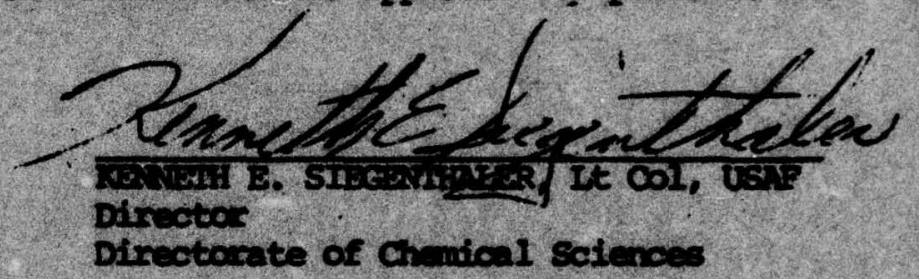

$\operatorname{ran} \operatorname{tin} 6$

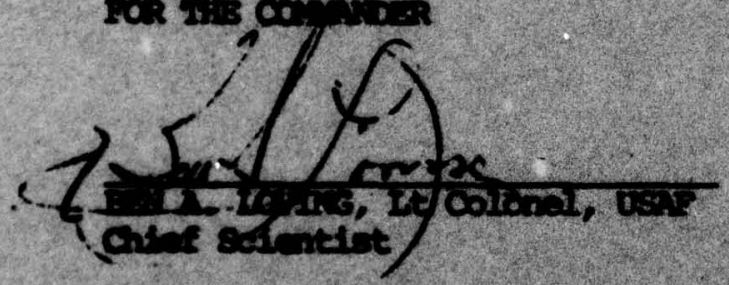

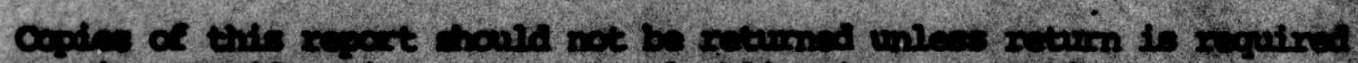

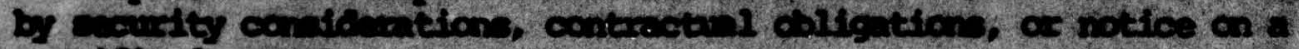
inats docinit.

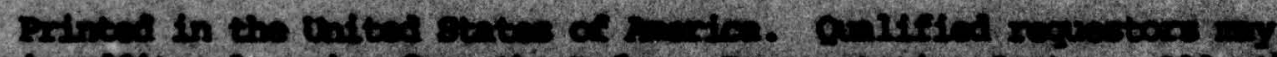

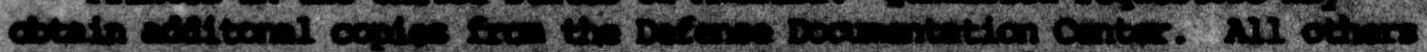

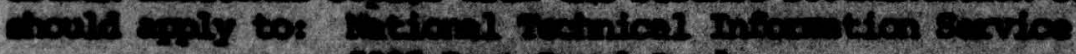

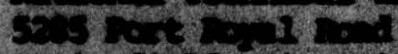

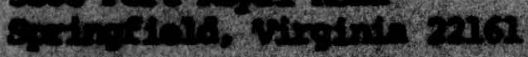


URITY CLASSIFICATION OF.THIS PAGE (Whon Date Entorod)

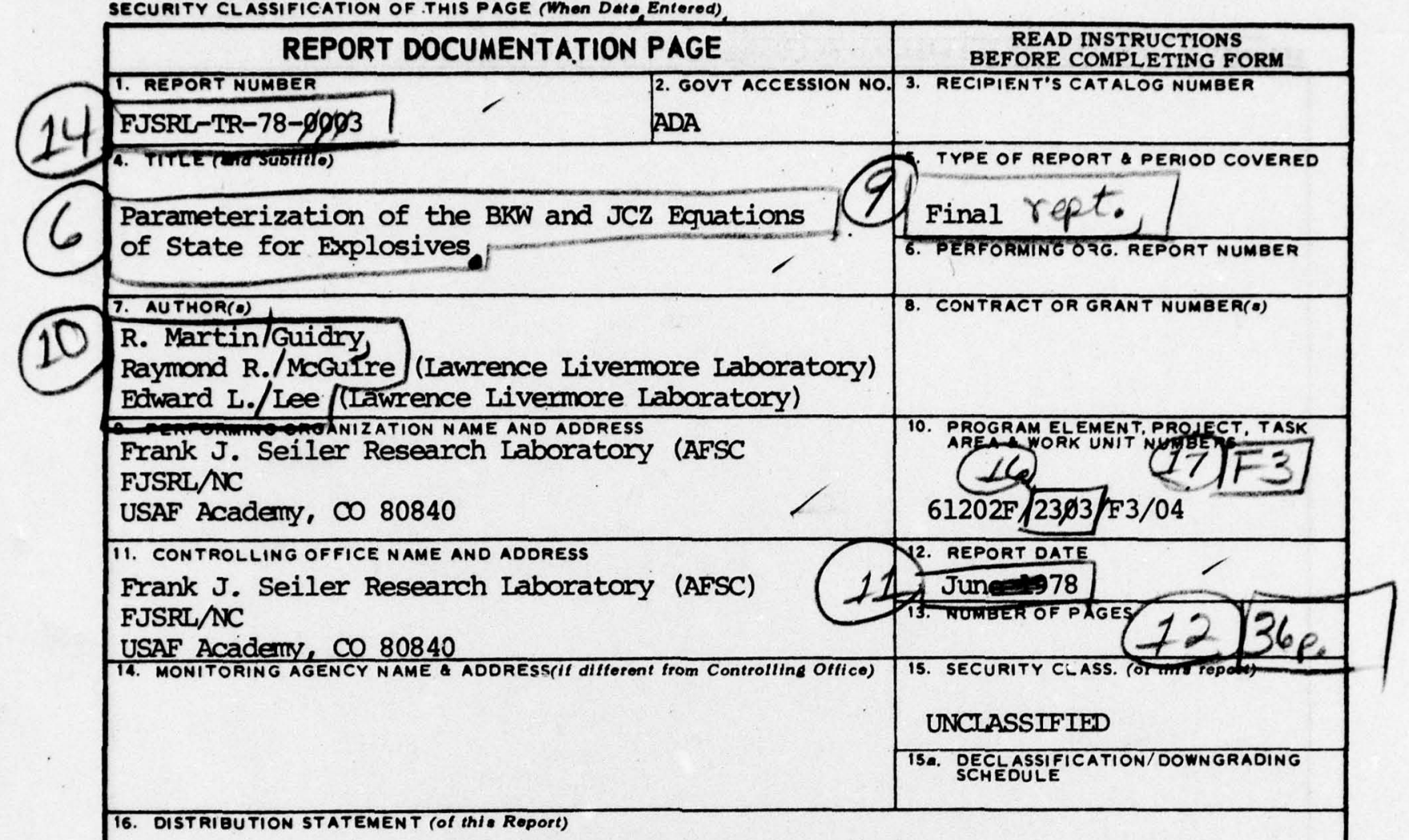

Approved for public release; distribution unlimited.

17. OISTRIBUTION STATEMENT (ol the ebetract ontered in Block 20, 1 l dillorent lrom Roport)

18. SUPPLEMENTARY NOTES

19. KEY WOROS (Continue on reveres alde Il neceseary and ldontlly by block number)

BKW Equation of State Detonation Velocity

JCZ Equation of State Detonation Properties

Eguations of State Detonation Product Composition

Detonation Pressure Mathematical Modeling

20. ABSTRACT (Continue on reveres olde If noceseery and ldentlly by block number)

The BKW equation of state, an empirical equation of state, for predicting

detonation properties of explosives, has been successfully reparameterized. It satisfactorily predicts not only detonation pressures and velocities but also the detonation product composition for both ideal and non-ideal explosive camposition. An attempt was made to parameterize the JCZ3 equation of state which is derived from first principles. The attempt was unsuccessful. It is suggested that revision of the equation in the low pressure regime may be necessary.

DD, TORM 1473 EOITION OF I NOV GS IS OBSOLETE

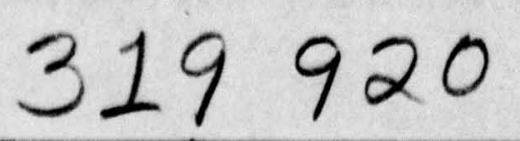

UNCLASSIFIED

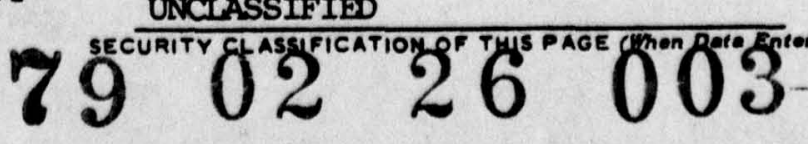


PARAMETERIZATION OF THE BKW AND

JCZ EQUATIONS OF STATE FOR EXPLOSIVES

R. Martin Guidry

Raymond R. MoGuire

Edward L. Lee

TECHNICAL REPPORT SRL-TR-78-0003

JUNE 1978

Approved for public release; distribution unlimited

DIRDCTORATE OF CHEMICAL SCIEAYCES

FRANK J. SEIIJFR RESEARCH IABORATORY

AIR FORCE SYSTEMS COMMAND

USAF ACADEMY, COLORADO 80840 
SRI-TR-78-0003

TABLE OF CONIENTS

SECTION

PAGE

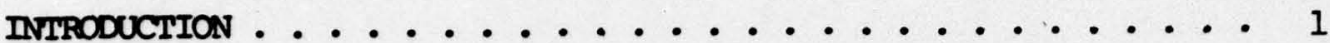

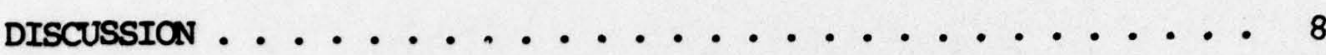

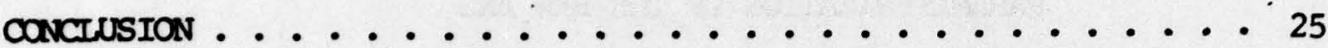

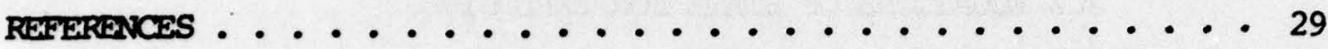

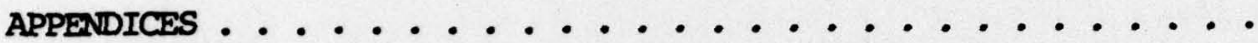

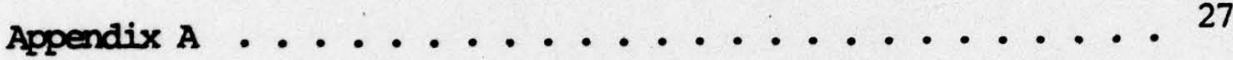

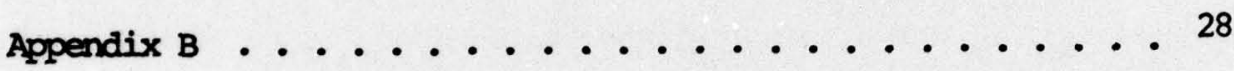

ii 


\section{INIRODUCTION}

Computer codes for calculating realistic detonation properties are important for predicting the performance of high explosives and for assessing the usefulness of new explosive formulations. Furthermore, tremendous cost and manpower savings can be realized by the judicious use of computer codes employing an equation of state that realistically predicts detonation properties. By properly employing the computer model, the chemist can eliminate or reduce research areas showing little promise (thus saving synthesis and property evaluation costs) and concentrate on research areas offering the greatest chance of success.

The most widely used equation of state for predicting the detonation properties of condensed explosives is the semiempirical Becker-KistiakowskyWilson (BKW) equation of state. This equation of state has been incorporated in thermo-hydro codes such as Fortran-BKW', RUBY ${ }^{2}$, and TIGER ${ }^{3}$. The original equation, based on a Kistiakowsky and Wilson ${ }^{4}$ modification of an equation developed by Becker $5,6,7$, has undergone many adaptions $8,9,10$, before obtaining its current, widely used form ${ }^{11}$.

$$
\frac{P V}{\text { RT }}=1+x e^{\beta X}
$$

where $x=\kappa \sum_{i} n_{i} k_{i} /\left[v(T+\theta)^{\alpha}\right]$

In equation (1) $P$ is the pressure of the system, $V$ is the volume, $T$ is the absolute temperature, and $\mathrm{R}$ is the ideal gas constant. The parameters $\alpha, \beta, K$, and $\theta$ are empirical in nature while $k_{i}$ is the covolume factor

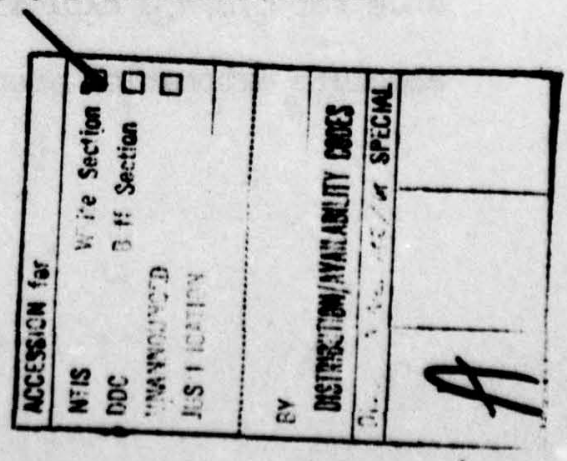


of the $i^{\text {th }}$ detonation product species and $n_{i}$ is the number of moles of the $i^{\text {th }}$ detonation product species.

This equation was initially fit to experimental detonation data by Cowan and Fickett ${ }^{11}$ in 1956. Later Mader ${ }^{12}$ re-parameterized BKW to give the set of parameters $\left(\alpha, \beta, k, \theta, k_{i}^{\prime} s\right)$ presently used in the FortranBKW code. These are shown in Tables I and II. Slightly different parameters are incorporated in the RUBY and TIGER codes.

To determine the best BKW parameters, one adjusts $\alpha, \beta, K$ and $\theta$ and the covolume factors, $k_{i}$, of the appropriate detonation product species to fit the best explosive performance data available. An estimate of the covolume factor of each species is obtainable through the hard sphere repulsion potential, $r^{*}$, for that species. The covolume factor and hard sphere repulsion potential are gecmetrically related. In the early 1960s, Mader $^{12}$ adjusted the BKW parameters to fit five experimental measurements involving two explosives, trinitrotoluene (TNT) and cyclotrimethylene trinitramine (RDX), and experimental hugoniot data for the detonation species $\mathrm{H}_{2} \mathrm{O}, \mathrm{N}_{2}$, and $\mathrm{CO}_{2}$. Using this limited data set, Mader found that two sets of parameters $(\alpha, \beta, k, \theta)$ were required. (See Table I.) One set of parameters was needed for high density explosives whose detonation products contain a large amount of solid carbon (TNT-type). A second set of parameters was required for explosives whose detonation products contain a relatively small amount of solid carbon (RDX-type). Using these two parameter sets, the predictions of relative explosive performance for $\mathrm{C}, \mathrm{H}, \mathrm{N}, \mathrm{O}$ explosives have been fairly reliable. Furthermore, absolute detonation pressures and velocities are calculated reasonably 
well as long as the explosive is a $\mathrm{C}, \mathrm{H}, \mathrm{N}, \mathrm{O}-$ type, is ideal, is near or slightly lower than $\infty$ balance and is at a high percentage of the theoretical maximum density. However, on an absolute scale the BKW predictions have not generally been accurate. Furthermore, where extremes in explosive compositions are investigated, predictions of the relative behavior are also in error. This error in relative behavior is also found when BKW predictions are made for non- $\mathrm{C}, \mathrm{H}, \mathrm{N}, \mathrm{O}$ explosives. The greatest deficiency of the BKW Equation of State is that it contains no attraction potential. For this reason it can be calibrated to a single point in PVT-space (as a G point); however, it then fits badly at all other points. Furthemore, the farther the calculated point is fram the point of calibration, the worse the fit will be. Thus it is impossible to predict isentrope shapes with the BKW Equation of State. 
Table I. Fortran-BWK Parametors for Explosives ${ }^{a}$

BKW Parameter

$a$

B

K

$\theta$
TNT-type value ${ }^{a}$

0.50

0.09585

12.685

400.
RDX-type value ${ }^{a}$

0.50

0.16

10.91

400.

$a_{\text {Reference }} 12$. 
Table II. Fortran-BNK Covolumes for Cammon Detonation Product Species ${ }^{a}$

\begin{tabular}{ll}
\hline $\begin{array}{c}\text { Detonation } \\
\text { Product } \\
\text { Species }\end{array}$ & $\begin{array}{c}\text { Covolume } \\
\left(\mathrm{k}_{i}\right)\end{array}$ \\
\hline $\mathrm{H}_{2} \mathrm{O}$ & 250 \\
$\mathrm{CO}_{2}$ & 600 \\
$\mathrm{CO}_{2}$ & 390 \\
$\mathrm{~N}_{2}$ & 380 \\
$\mathrm{NO}_{2}$ & 386 \\
$\mathrm{H}_{2}$ & 180 \\
$\mathrm{O}_{2}$ & 350 \\
$\mathrm{CH}_{4}$ & 528 \\
\hline
\end{tabular}

$a_{\text {Reference }} 12$. 
A second equation of state for predicting detonation properties is the Jacobs-Cowperthwaite-Zwisler (JCZ) equation of state. The equation of state, developed from first principles by Dr. Sigmund Jacobs ${ }^{13}$, has recently been incorporated into the TIGER computer code by cowperthwaite and Zwisler ${ }^{14,15}$. It is anticipated that the JCI equation of state, when properly parameterized. will offer vast improvements over the semi-empirical BKW equation of state in the calculation of not only the pressure and velocity of detonation, but also the detonation temperature, product composition and isentropic expansion from the detonation state. Unlike the BKW equation of state, the $\mathrm{JCZ}$ equation of state incorporates both a temperature-independent pressure term and a pressure term resulting from thermal motion. The generalized JCZ equation of state can be represented as

$$
P=P_{0}\left(V, n_{i} \cdots n_{s}\right)+G\left(T, V, n, \cdots n_{s}\right) N R T / V
$$

where $P$ is the total pressure of the system, $P_{0}$ is the temperatureindependent pressure term, $\mathrm{V}$ is the volume, $\mathrm{n}_{i}$ 's are the moles of the individual product species, $G$ is the Grïneisen parameter, $R$ is the ideal gas constant, $\mathrm{N}$ is the total moles of product species, and $\mathrm{T}$ is the absolute temperature of the system. Furthermore, the Grïneisen parameter G is composed of several terms - one of which is a potential function. The JCZ2 equation of state incorporates the MIE potential function while the JCZ3 equation of state, the subject of this report, employs an expo-p,m potential function. In the expo-p,m potential function

$$
\phi=\varepsilon\left\{\frac{m}{p-m} \exp \left[p\left(1-\frac{r}{r^{*}}\right)\right]-\frac{p}{p-m}\left(\frac{r^{*}}{r}\right)^{m}\right\}
$$


or

$$
\phi=\phi_{r}+\phi_{a}
$$

$\phi$ is the total potential for the pair of molecules, $\phi_{r}$ is the repulsion term, and $\phi_{a}$ is the attraction term. In equation (3) $\varepsilon$ is the absolute value of the potential at its minimu, $r$ is the molecular separation at the specified potential, $r^{*}$. is the molecular separation at the potential minimm, $\mathrm{p}$ is the repulsion parameter, and $\mathrm{m}$ is the attraction parameter. In parameterizing the JCZ3 equation of state, one must find a best attraction parameter $(m)$ and a best repulsion parameter ( $p$ ) for the equation as a whole as well as a set of potentials $\left(\varepsilon, r^{*}\right)$ for each product species encountered in the calculation. In theory it should be possible to determine these parameters from experimental Hugoniot data. 


\section{DISCUSSION}

Because of the limited amount of data used, Mader's parameterization 12 of BKW was severely restricted. With an expanded data base a more severe test of the parameterization will result. Since Mader's parameterization of $\mathrm{BKW}$ in 1963, much useful detonation data has appeared in literature. Not only do detonation pressure and detonation velocity data for a large number of explosives abound in the literature $16,17,23$, but in recent years several detonation product composition studies ${ }^{18,19,20,21}$ have also appeared. The approach used was to select several explosives displaying a wide variety of elemental compositions on which experimental detonation pressure as a function of loading density, detonation velocity as a function of loading density, and detonation product composition data was available. The explosives selected comprised both $\mathrm{C}, \mathrm{H}, \mathrm{N}, \mathrm{O}$ and non$\mathrm{C}, \mathrm{H}, \mathrm{N}, \mathrm{O}$ explosives. In Table III are listed the explosives used in this study along with their elemental compositions and experimental data available in the literature. This set of explosives should camprise a very severe test for any set of BKW parameters employed.

When the experimental detonation product composition and the BKW calculated Chapman-Jouget (CT) isentropes are compared for both HMX and $\mathrm{TNT}$, an interesting observation arises. Ornellas ${ }^{18}$ has noted that the detonation products resulting from heavily confined charges of HMX and TNT attain equilibrium under nonideal gas conditions between approximately $1500^{\circ} \mathrm{K}$ and $1800^{\circ} \mathrm{K}$. The RUBY code was used to calculate the $\mathrm{CJ}$ isentropes at these two temperatures for HMX and TNT. The experimental product camposition should then fall within the range of values for the 


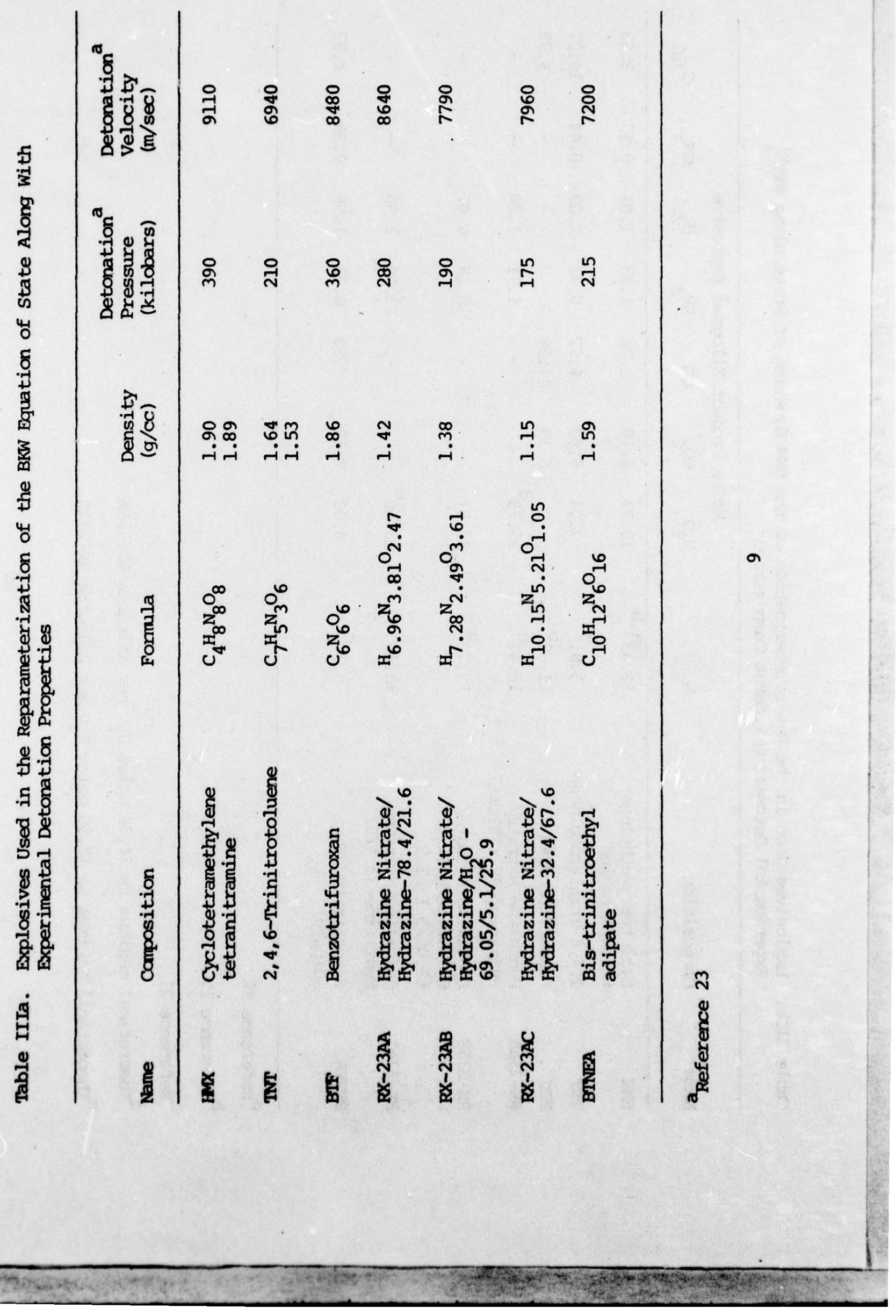




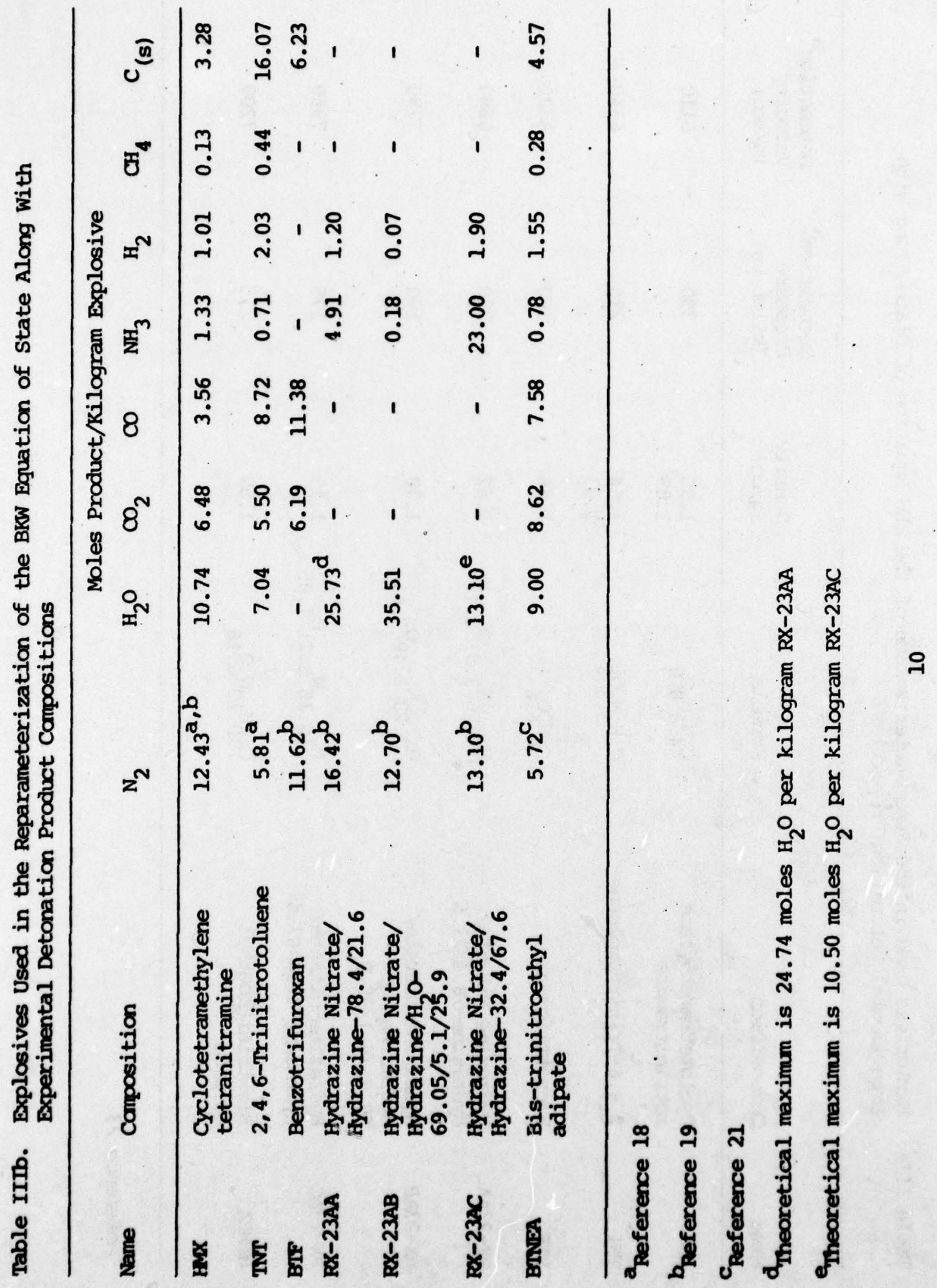


$1500^{\circ} \mathrm{K}$ and $1800^{\circ} \mathrm{K}$ calculated isentropes since in this range the product species composition is "frozen". The comparison can be seen in Table IV for HMX and TNT. In both cases it is immediately obvious that the calculated quantity of $\mathrm{CO}$ is much smaller than the observed quantity while the calculated amount of $\mathrm{CO}_{2}$ is much larger than the observed amount of this product species. Furthermore, the observed amount of $C_{(s)}$ falls very near the lower end of the calculated range for this product species.

The relative quantities of these three carbon-containing species are governed by equilibrium

$$
{ }^{200}(\mathrm{~g}) \rightleftharpoons \mathrm{C}_{2(\mathrm{~g})}+\mathrm{C}_{(\mathrm{s})}
$$

Mader assumed formation of carbon in the standard state (i.e., $\Delta \mathrm{H}_{f}=0$ ) ; however, it may be noted that the above equilibrium can be shifted to the left by increasing the heat of formation of $C_{(s)}$ - which is input into the computer. The BKW calculated isentropes would then contain more $\mathrm{CO}$ and less $\mathrm{CO}_{2}$ and $\mathrm{C}_{(\mathrm{s})}$. This is in the correct direction to satisfy the deficiencies discussed above. It was thus decided to add an additional parameter - the heat of formation of $C_{(s)}$ - in the reparameterization of the BKW equation of state. Added impetus to this decision was the observation that the carbon produced was not graphite but an amphorous form. Additionally, several other researchers (particularly scientists at Lawrence Livermore Laboratory and in the Soviet Union) were using positive heats of formation for carbon in their computer codes.

There are very few measurements of detonation temperatures at the CT state and these have relatively large uncertainties ${ }^{12,22}$. Nevertheless, it was intuitively felt that the calculated detonation temperatures should 
be higher. For a fixed set of the other BKW parameters, $\left(\alpha, \beta, k, k_{i}{ }^{\prime} s\right)$, the larger the value of the parameter $\theta$, the higher the calculated detonation temperature.

The approach taken, therefore, in reparameterizing the BKW equation of state was the systematic variation of the five empirical parameters $\left(\alpha, B, k, \theta\right.$ and $\Delta \mathrm{H}_{f}$ ) while providing for the dependence of detonation temperature on $\theta$ and the dependence of equation (5) on the heat of formation of $C_{(s)}$. Additionally, each product species has a characteristic covolume, $k_{i}$. These product species' covolumes were also treated as empirical parameters; however, they were constrained within certain, reasonable limits and not allowed to completely vary. In the parameterization, not only were detonation pressures and velocities used in the fit, but also product camposition. Furthermore, the fit was extended to include the non- $\mathrm{C}, \mathrm{H}, \mathrm{N}, \mathrm{O}$ explosives $\mathrm{BTF}, \mathrm{RX}-23 \mathrm{AA}, \mathrm{RX}-23 \mathrm{AB}$ and $\mathrm{RX}-23 \mathrm{AC}$ as well as the $\mathrm{C}, \mathrm{H}, \mathrm{N}, \mathrm{O}$ explosives HMX, TNT and BINEA. These extensions should give a very severe test of the BKW equation of state both from the standpoint of the wide range of explosive properties used in the parameterization as well as the types of explosives employed in the fit attempt.

The results of this "brute force" parameterization attempt are given in Tables V and VI. The "best" fit set of parameters and product specie colvolumes are displayed in Table VII. The results shown in Tables $\mathrm{V}$ and vI are exceptionally good considering the wide range of detonation properties fit and the various types of explosives used. Comparison of calculated results with experimental data demonstrates that the differences between the two are usually within the known experimental error which is 


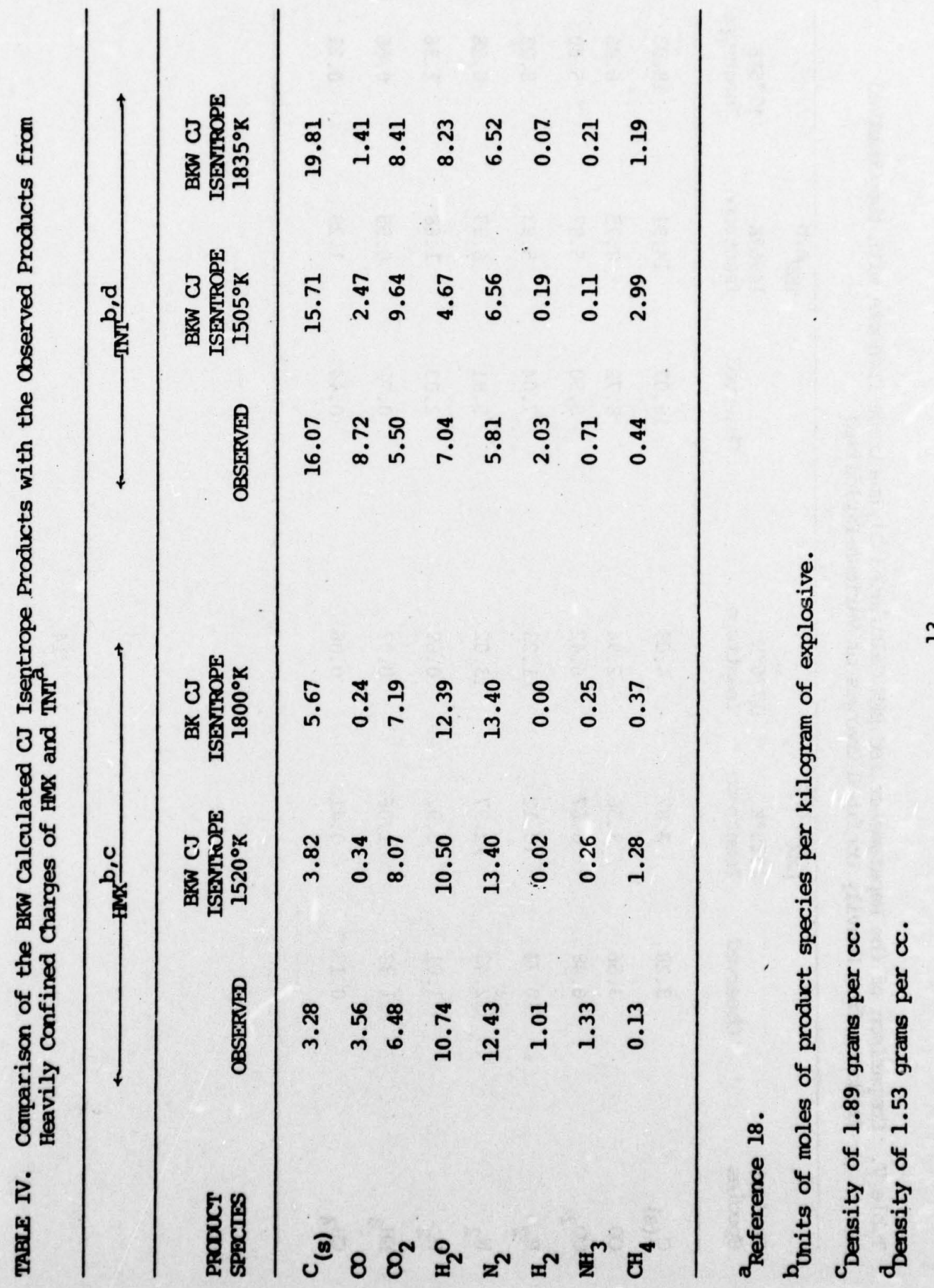




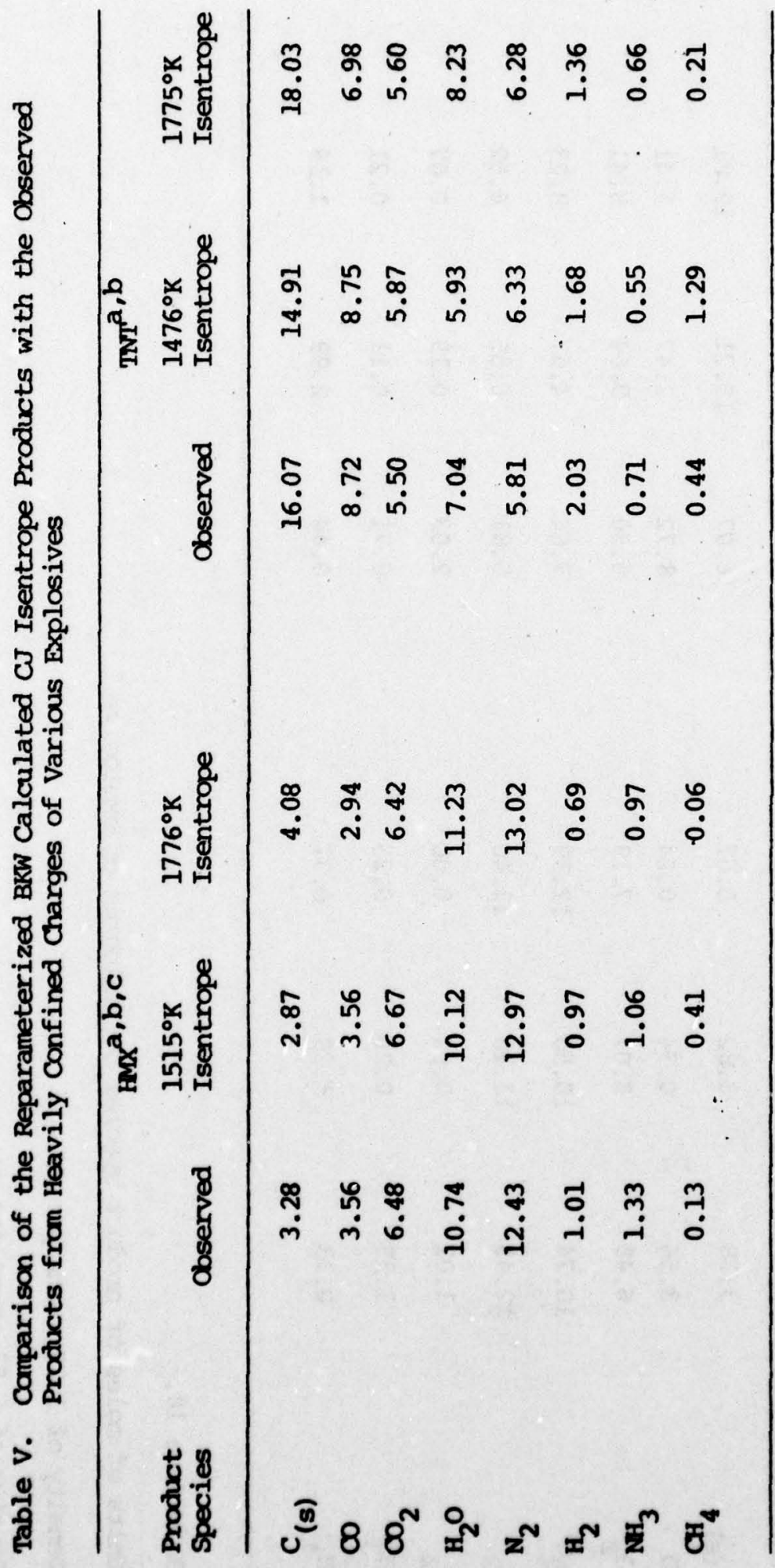




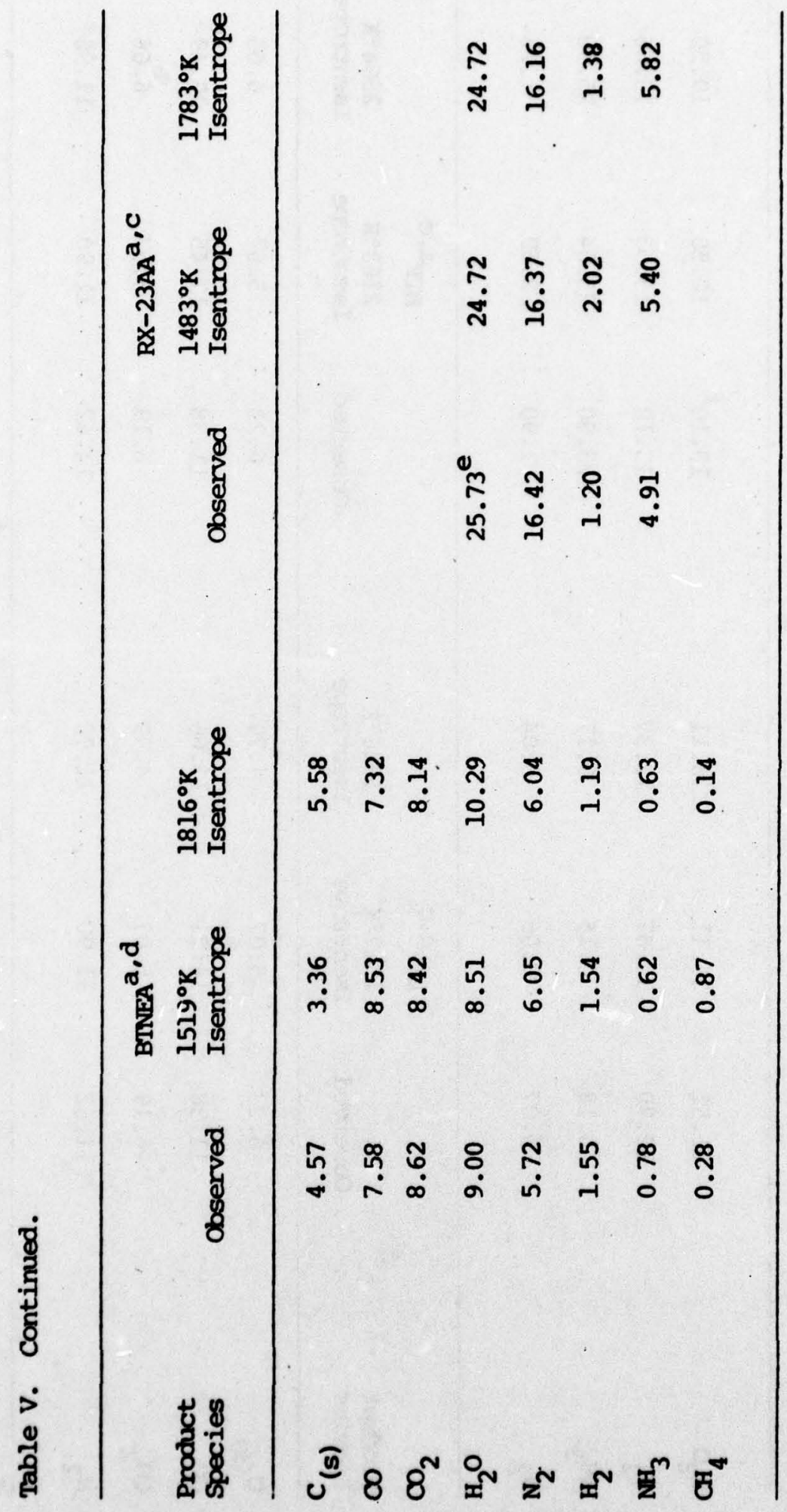




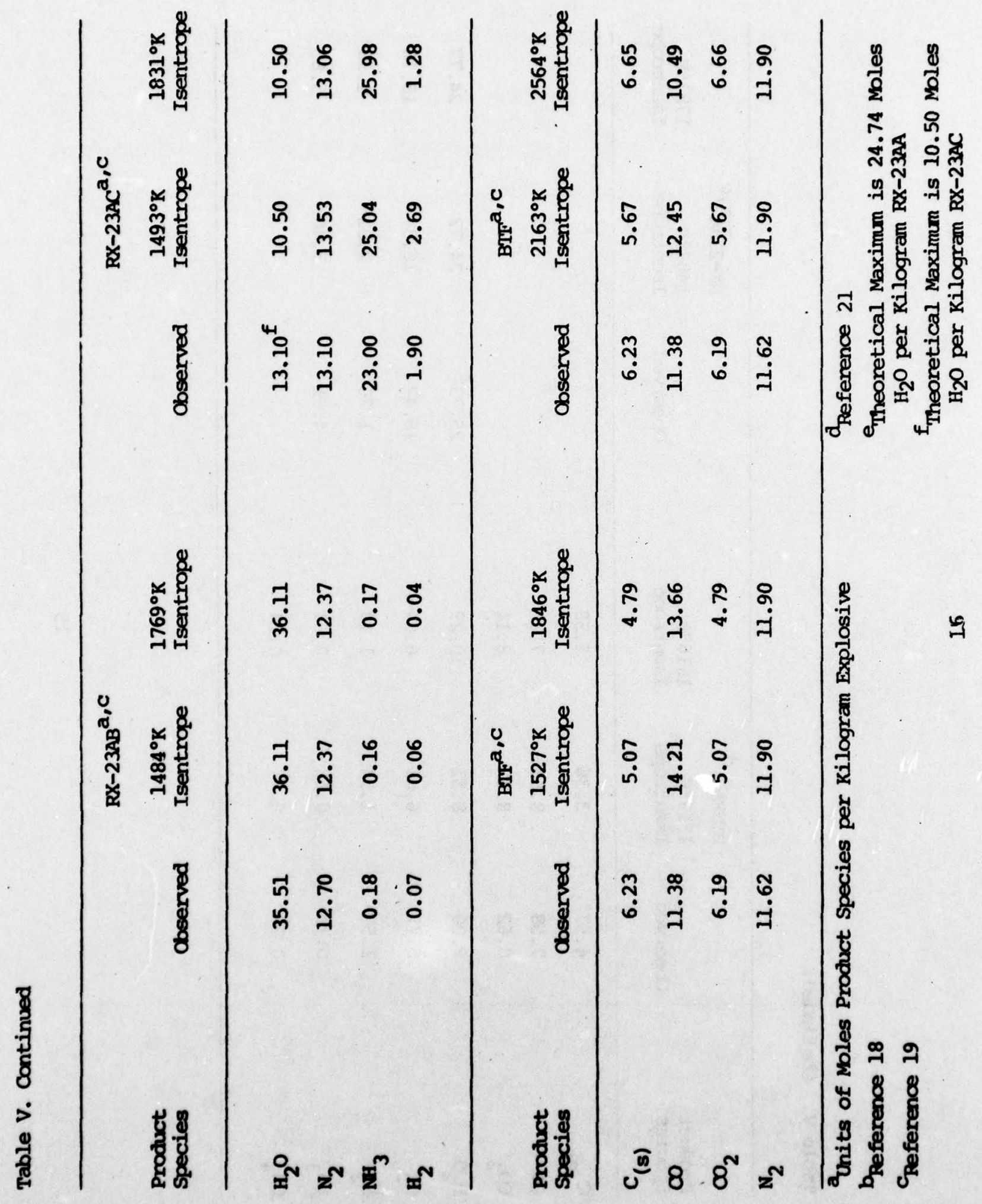




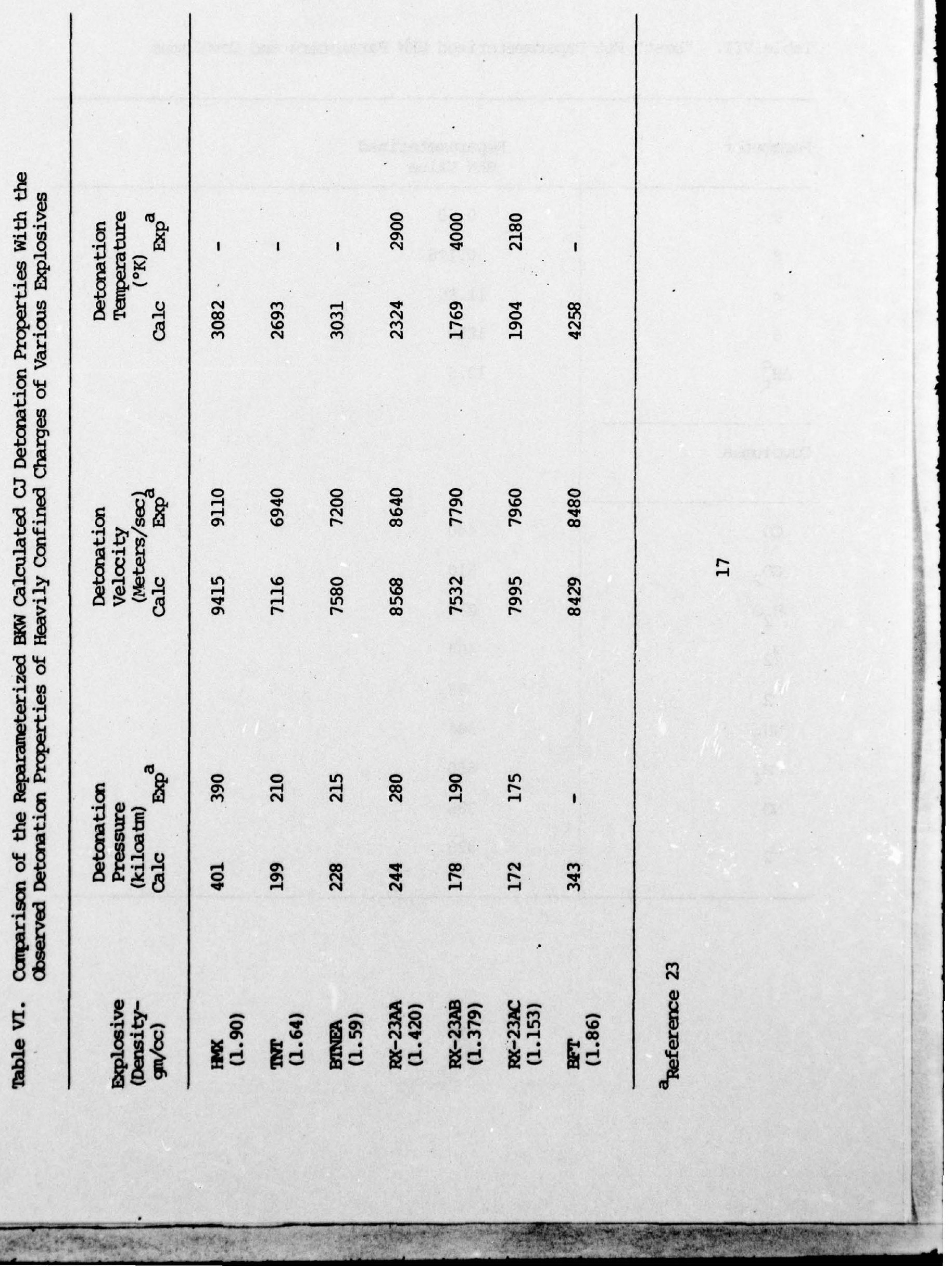


Table VII. "Best" Fit Reparameterized BKW Parameters and covolumes

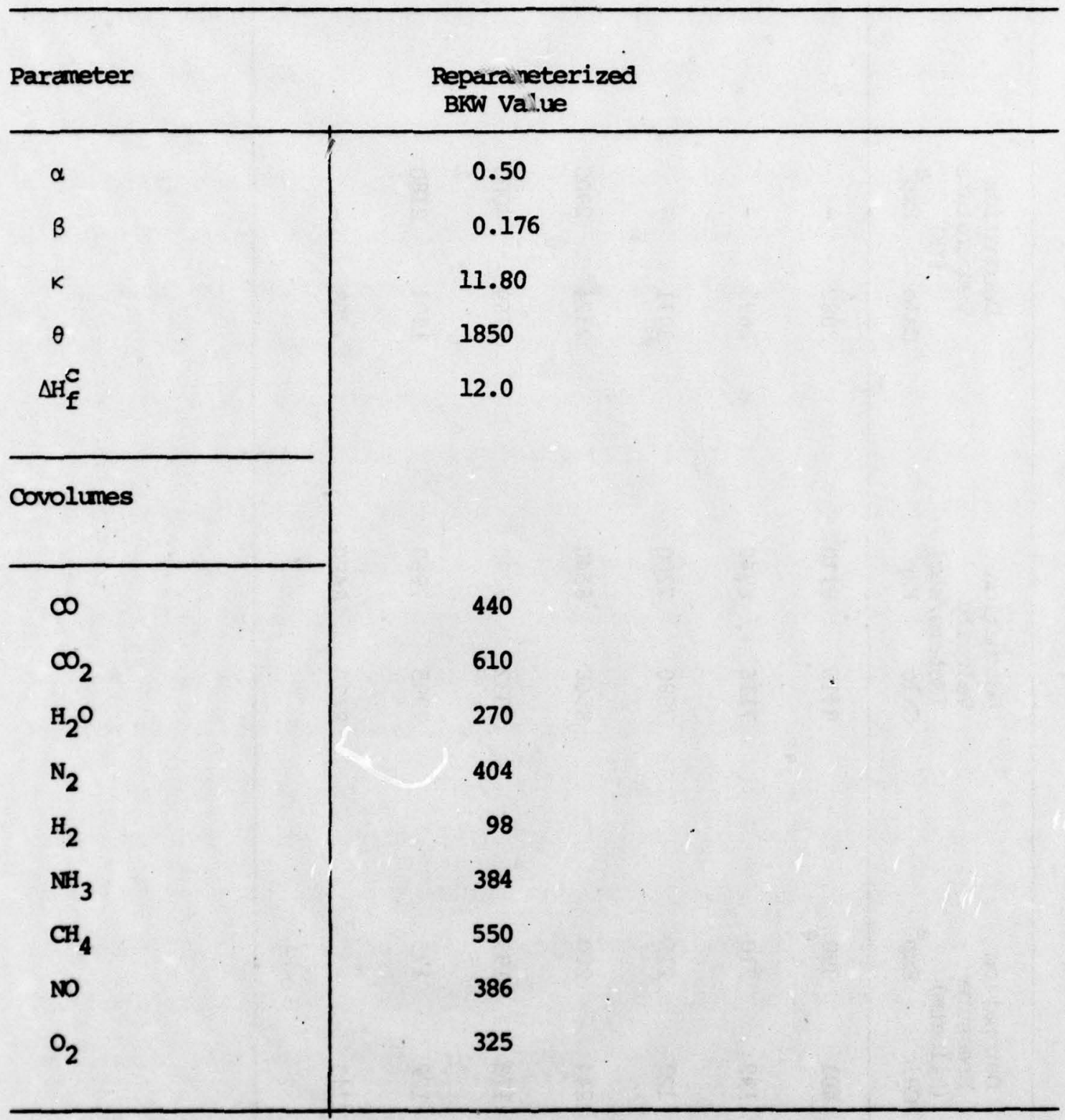

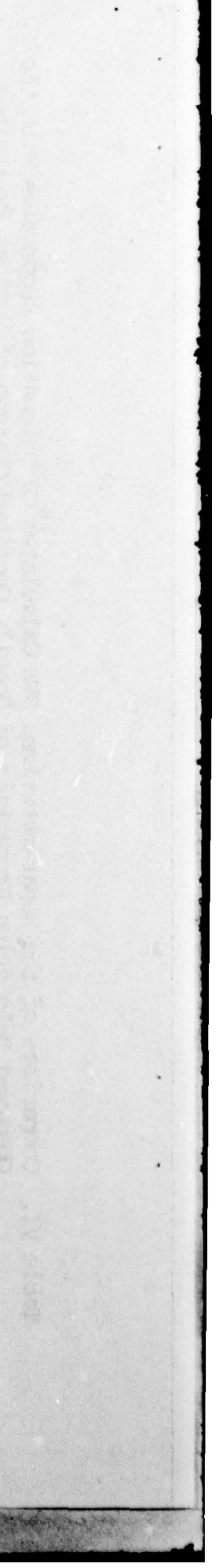


generally no better than 5\%. Again in accordance with ornellas' findings (18), a "freeze-out" temperature range of $1500^{\circ} \mathrm{K}-1800^{\circ} \mathrm{K}$ has been employed for calculated detonation product camposition data.

Because the JCZ3 equation is developed from first principles and, therefore, the parameters do have physical significance, it was felt that a purely "brute force" type of fit would be unsatisfactory. The values assigned to the parameters should be determined from experimental data and, therefore, should be physically meaningful. Fortunately, for many of the detonation product species, experimental Hugoniot data does exist. For each of these product species then, the pair potential parameters $\left(\varepsilon / k, r^{*}\right)$ can be determined. First, however, the attraction and repulsion parameters $(m, p)$ of the JCZ equation of state must be set. Because this equation of state was ideally written for spherical molecules in a face-centered cubic (fcc) lattice structure, it is necessary to find experimental Hugoniot data for a spherical molecule with a face-centered cubic lattice structure that can be used to set the value of the attraction and repulsion parameters as well as its own pair potential parameters. A molecule for which much experimental data is available and which satisfies the above requirements is argon $(24-28)$. Once the attraction and repulsion parameters are determined from argon Hugoniot data, they are used unchanged in the determination of the pair potential parameters for each of the detonation product species. Because the product species are not generally of a spherical shape and often do not pack in a face-centered cubic lattice structure, small deviations from the "true" pair potential values are expected. The detonation product species for which experimental 
Hugoniot data are available are water $\left(\mathrm{H}_{2} \mathrm{O}\right)(29)$, nitrogen $\left(\mathrm{N}_{2}\right)(30,31)$, carbon dioxide $\left(\mathrm{CO}_{2}\right)(30)$, oxygen $\left(\mathrm{O}_{2}\right)(32)$, and hydrogen $\left(\mathrm{H}_{2}\right)(28,33-35)$.

The procedure used in establishing the values of the attraction and repulsion parameters and the pair potential parameters was to use the TIGER computer code to calculate a Hugoniot curve for the species of interest. This curve was compared with the experimental Hugoniot curve. Adjustments were made to the parameters until the fit was within experimental error. By working with Hugoniot data in setting the parameter values as opposed to actual detonation property data of explosives, one restricts the number of variables that must be simultaneously adjusted to obtain a reasonable fit. With the exception of argon, only two variables must be adjusted to obtain the pair potential parameters for any one species. If detonation property data were employed, one would be required to simultaneously adjust all of the pair potential parameters of the product species as well as the attraction and repulsion parameters. This would be a very laborious task. Furthermore, it is very likely that the "best" fit pair potential parameters could no longer be related to physical properties of the system since there would be a tendency to spread deviations over all parameters. It is essential, therefore, that care be taken to insure realistic values for the pair potential parameters. Estimates of these parameters, based on physical measurements, can be obtained from several sources $(13,36,37)$. It should be remembered that the calculated parameters will vary slightly from the measured values because of the restrictions of the JCZ3 equation of state. Once the pair potential parameters of species for which experimental hugoniot data exist have been determined, 
then these parameters for the other product species $\left(\mathrm{CH}_{4}, \mathrm{NH}_{3}, \mathrm{NO}, \mathrm{CO}\right)$ must be evaluated. This can be accomplished by obtaining initial estimates $(13,36,37)$ of the parameters and then using detonation product data from several explosives. As new product species are added to the TIGER library, it will be necessary to determine the pair potential parameters.

In order to facilitate the parameterization of the JCZ3 equation of state, a subroutine was incorporated into the TIGER computer program. This subroutine, based on the method of Bevington (38), simultaneously varies either two $\left(\varepsilon / k, r^{*}, p\right)$, three $\left(\varepsilon / k, r^{*}, p\right)$, or four parameters $\left(\varepsilon / k, r^{*}, p, m\right)$ until a "best" fit set of parameters are obtained. The "best" fit parameters are ascertained by a comparison of the experimental Hugoniot data, which is input, and the calculated Hugoniot data. A "quality of fit" parameter was used to determine when a satisfactory fit of the Hugoniot data is obtained. For all species except argon only the twoparameter option was employed. With argon, both the three- and the fourparameter options were used in an attempt to obtain a satisfactory fit. When the three-parameter option was employed, the value of the attraction parameter was set equal to 6.0 for which there appears to be same theoretical justification (36).

This attempt to parameterize the JC23 equation of state has demonstrated two major problem areas. In the analysis of argon attempts to vary all four parameters $\left(\varepsilon / k, r^{*}, p, m\right)$ met with no success - primarily because the temperature of the system reached extremely high values during the calculations causing the program to terminate with an error. This is strictly a software problem - not a theoretical one. When the attraction 
parameter was set at 6.0 and the other three parameters for argon were varied, a minimm chi square value was obtained. At this minimm the repulsion parameter was $14.330, \varepsilon / k$ was 48.98 and $r^{*}$ was 3.93 . However, when the attraction parameter was set at 6.0 , the value of the repulsion parameter was readjusted for each run and only two parameters were simultaneously varied, no overall minimm could be located. These results are shown in Table VIII. The value of the chi square appears to vary inversely with the value of the repulsion parameter. At values of the repulsion parameter above 14.5, the calculated temperatures become extremly high and the program terminates by error. Furthermore, the values of the pair potential parameters became very unrealistic for high values of "p". No explanation is forthcoming about why the two points at "p" equal to 14.33 are not equivalent. It is most certainly due to a peculiarity in the fitting subroutine. The second problem area concerns the fit of the calculated Hugoniot curve to the experimental Hugoniot curve. The data shown in Table IX is typical of that obtained on all fit attempts. The calculated and experimental Hugoniot curves typically fit very well at the high pressure segment of the curve; however, at the lower pressures (below 30 kiloatmospheres) the fit becames increasingly unsatisfactory. This result demonstrates the need to reexamine the JCZ3 equation of state particularly at the low pressure end where most of the detonation products are in the gas phase or between the gas and normal liquid state. Because no values of the attraction and repulsion parameters could be obtained, the parameterization attempt is suspended until the reevaluation of the JCZ3 equation of state is accomplished. 
Table VIII. Attempted Fit for Liguid Argon Hugoniot ${ }^{a}$ Using Simultaneous Variation of $\varepsilon / k$ and $r^{*}$ with $m=6.0$ and Various Input Values of $\mathrm{p}$.

\begin{tabular}{cccc}
\hline$p$ & $\varepsilon / k$ & $r^{*}$ & Chi square \\
\hline 12.0 & 450.0 & 3.34 & 26.51 \\
12.50 & 315.1 & 3.43 & 21.28 \\
13.00 & 210.3 & 3.53 & 17.91 \\
13.50 & 136.5 & 3.65 & 15.73 \\
13.60 & 125.0 & 3.67 & 15.41 \\
13.70 & 114.1 & 3.70 & 15.10 \\
13.90 & 94.2 & 3.75 & 14.57 \\
14.00 & 86.4 & 3.77 & 14.33 \\
14.33 & 63.2 & 3.87 & 13.70 \\
14.50 & 53.5 & 3.91 & 13.43 \\
\hline
\end{tabular}

$a_{\text {Reference }} 26$. 
Table IX. Typical Fit Attempt of Calculated and Experimental Hugoniot curves for Liquid Argon $\left(\varepsilon / k=48.98, r^{\star}=3.93, p=14.33\right.$, $\mathrm{m}=6.00$ )

\begin{tabular}{|c|c|c|c|}
\hline $\begin{array}{l}\text { Input Volume } \\
(\infty \mathrm{c} / \mathrm{gm})\end{array}$ & $\begin{array}{l}\text { Exp. Pressure } \\
\text { (atmos.) }\end{array}$ & $\begin{array}{l}\text { Calc. Pressue } \\
\text { (atmos) }\end{array}$ & \& Error \\
\hline 0.5585 & 6713. & 12253. & 45.2 \\
\hline 0.5259 & 11727. & 16535. & 29.1 \\
\hline 0.5026 & 17965. & 21141. & 15.0 \\
\hline 0.4851 & 25426 . & 25955. & 2.0 \\
\hline 0.4780 & 30000 & 28385 & -5.7 \\
\hline 0.4600 & 40000 & 36189 & -10.5 \\
\hline 0.4460 & 50000 & 44545. & -12.2 \\
\hline 0.4316 & 59421. & 56210 & -5.7 \\
\hline 0.4184 & 74064 & 71090. & -4.2 \\
\hline 0.4071 & 90248. & 88163. & -2.4 \\
\hline 0.3975 & 107973. & 107400 & -0.5 \\
\hline 0.3892 & 127237. & 128681 & 1.1 \\
\hline 0.3819 & 148042 & 151793. & 2.5 \\
\hline 0.3754 & 170386 & 176426 & 3.4 \\
\hline 0.3697 & 194272. & 202156 & 3.9 \\
\hline 0.3646 & 219697. & 228480 & 3.8 \\
\hline 0.3600 & 246663. & 254819 & 3.2 \\
\hline 0.3558 & 275169. & 280618. & 1.9 \\
\hline 0.3520 & 305215 & 305429 & 0.0 \\
\hline 0.3486 & 336801 & 328938 . & -2.4 \\
\hline 0.3454 & 369928. & 351005. & -5.4 \\
\hline
\end{tabular}

a Reference 26. 


\section{CONCLUSION}

The BKW equation of state has been successfully reparameterized. The reparameterized version of this equation of state is far superior to any previous versions in that it not only satisfactorily predicts detonation pressures and detonation velocities for ideal $(\mathrm{C}, \mathrm{H}, \mathrm{N}, \mathrm{O})$ explosives, but also predicts these properties as well as detonation product compositions for both ideal and non-ideal explosives. The two major changes in the reparameterization were a significant increase in the value of the parameter $\theta$ and the addition of a fifth parameter - the heat of formation of amorphous carbon. In considering the data in Table $\mathrm{v}$, one notes that BTF is the only explosive where significant deviations fram the experimental data are calculated. It is believed that for BTF the "freeze out" temperature range may be significantly higher than the $1500^{\circ}-1800^{\circ} \mathrm{K}$ range employed. BTF appears to be a much hotter-burning explosive than any of the other explosives used. As shown in Table $\mathrm{V}$, when a $2150^{\circ}-2550^{\circ} \mathrm{K}$ "freeze-out" range is used, the fit is very good. Another point should be noted regarding this reparameterized BKW equation of state. After the reparameterization was campleted, an error in one of the methane thermodynamis constants (15) was discovered. The thermodynamic constants for all product species are given in Appendix A. As long as the reparameterized $\mathrm{BKW}$ equation of state is used with this incorrect value, the results should be satisfactory. The new parameters compensate for the error in the incorrect methane thermodymamic constant. If this error is corrected, a new parameterization must be accomplished. 
Attempts to parameterize the JCZ3 equation of state were unsuccessful. It is felt that the primary reason for this is that the equation itself needs to be revised in order to better calculate detonation properties at lower pressures. Once the equation has been revised, attempts at paramoterization of the equation can continue. Once satisfactorily parameterized, the JCZ3 equation of state should be far superior to any other equation of state currently being used. 


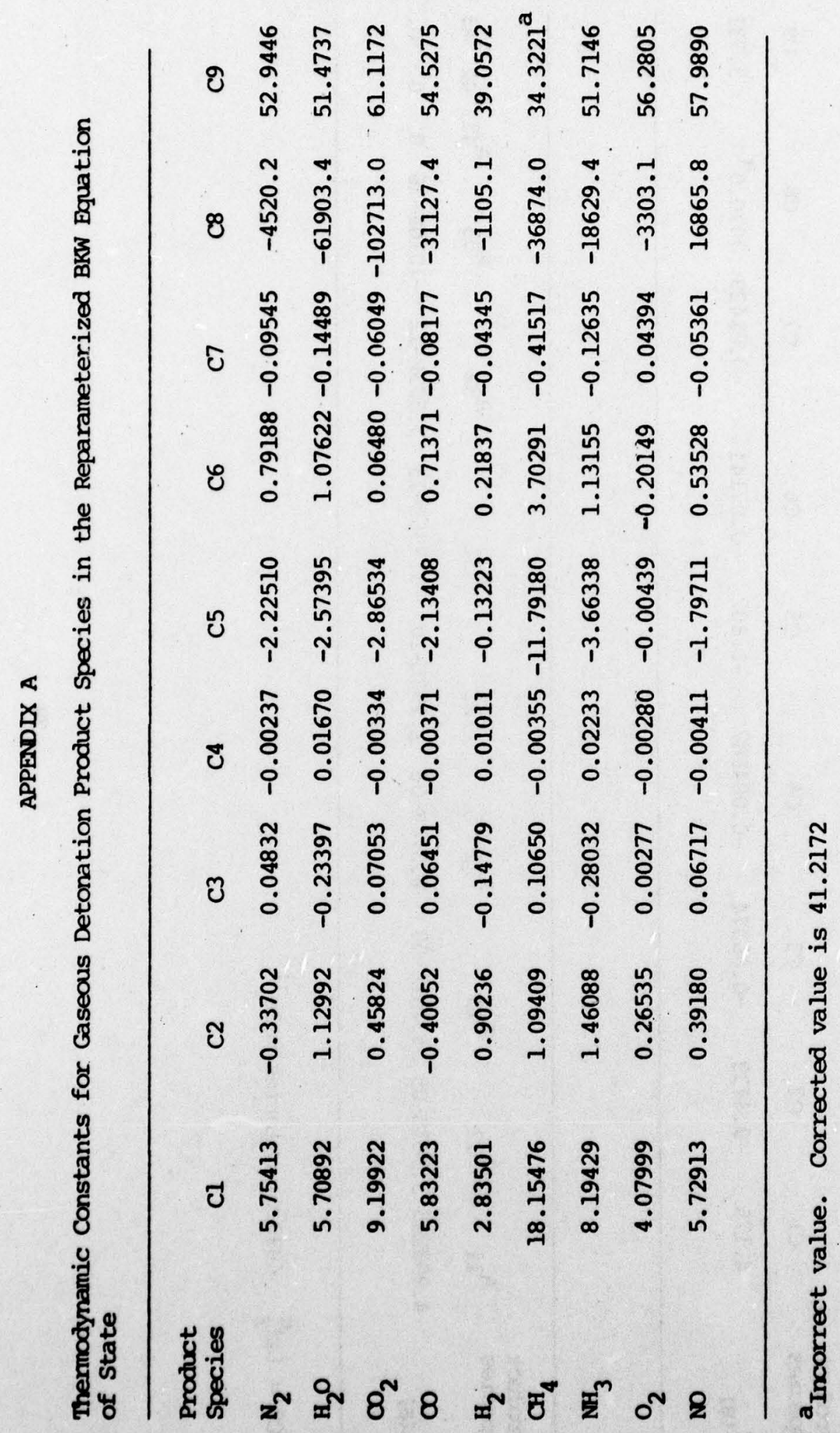

ล 


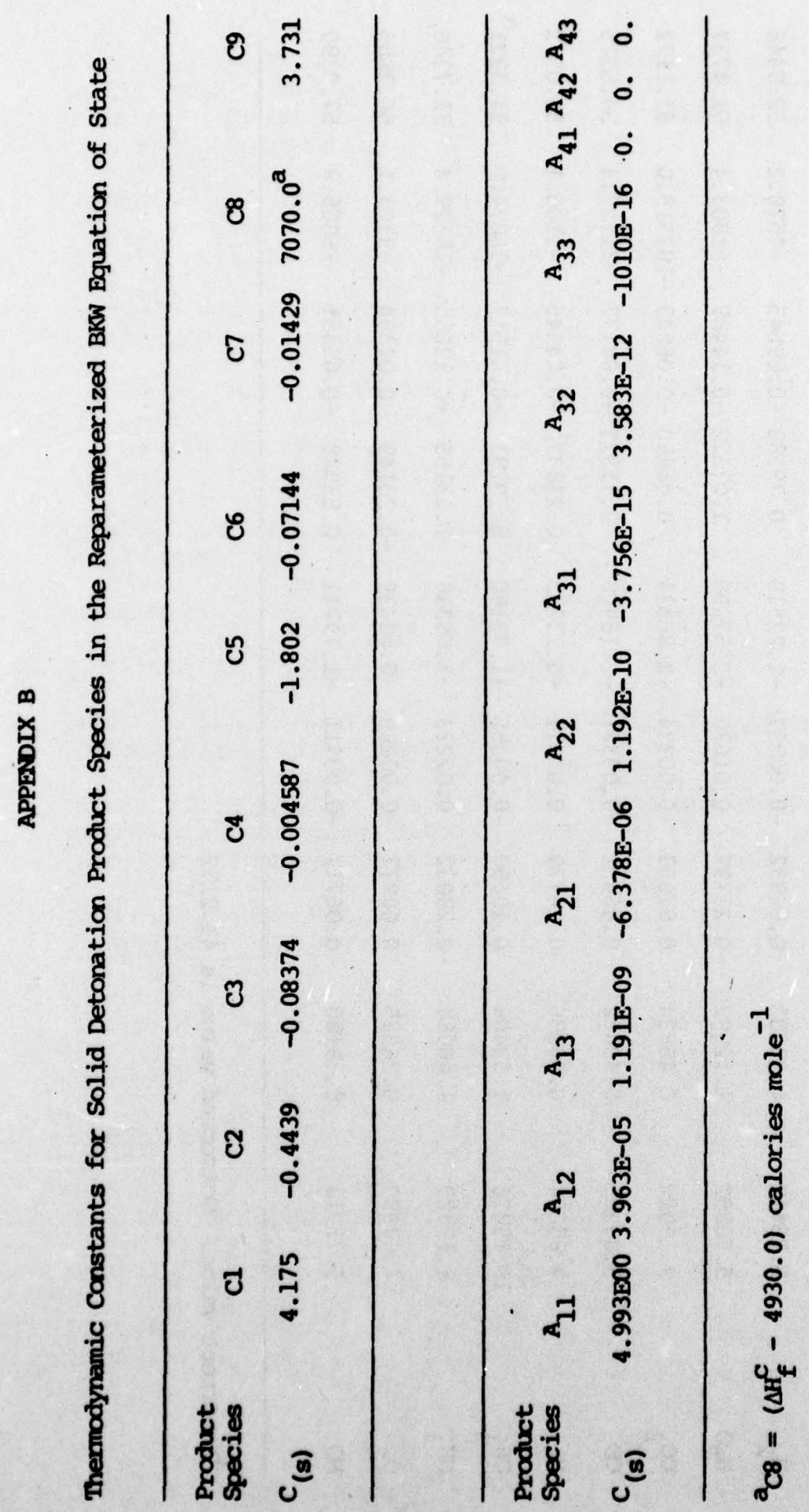


REFERENCES

(1) Mader, C.L., "FORIRAN-BKW: A Code for Computing the Detonation Properties of Explosives," Lost Alamos Scientific Laboratory Report No. LA-3704, 10 July 1967.

(2) Levine, H.B. and Sharples, R.E., "Operator's Manual for RUBY," Lawrence Radiation Laboratory Report No. UCRL-6815, 20 March 1962.

(3) Wiebenson, W.E. Zwisler, W.H., Seely, L.B. and Brinkley, S.R., Jr., "TIGER Documentation Volume," Stanford Research Institute (prepared for Ballistic Research Laboratory, Aberdeen, Maryland - Contract No. DA-04-200-AMC-3226 (X), Nov. 1968), SRI Publication No. 2106.

(4) Kistiakowsky, G.B. and Wilson, E.B., "Repoitt on the Prediction of Detonation Velocities of Solid Explosives," Office of Scientific Research and Development Report OSRD-69 (1941).

(5) Becker, R., z. Physik., 4, 393 (1921).

(6) Becker, R., Z. Physik., 8,321 (1922).

(7) Becker, R., Z. Technische Physik., 3, 249 (1922).

(8) Kistiakowsky, G.B. and Wilson, E.B., "The Hydrodynamic Theory of Detanation and Shock Waves," Office of Scientific Research and Development Report OSRD-114 (1941).

(9) Brinkley, S.R., Jr. and Wilson, E.B., "Revised Method of Predicting the Detonation Velocities in Solid Explosives," Office of Scientific Research and Development Report OSRD-905 (1942).

(10) Kirkwood, J.B., Brinkley, S.R., Jr., and Richardson, J.M., "The Pressure Wave Produced by an Underwater Explosion: Part $V, "$ Office of Scientific lesearch and Development Report OSRD-2022.

(11) Cowan, R.D. and Fickett, W., J. Chem. Phys,., 24, 932 (1956).

(12) Mader, C.L., "Detonation Properties of Condensed Explosives Computed Using the Becker-Kistiakowsky-Wilson Equation-of-State," Ios Alamos Scientific Laboratory Report No. LA-2900, 17 June 1963.

(13) Jacobs, S.J., Quarterly Progress Reports on "Equation of State for TICXR," Covering the periods $15 \mathrm{Mar}$ to $1 \mathrm{Jul} 1971,15 \mathrm{Jul}$ to $20 \mathrm{Sep}$ 1971, 20 Sep to 31 Dec 1971, 1 Apr. to 30 Sep 1972, 1 Oct to $30 \mathrm{Dec}$ 1972, I Jan to 31 Aug 1973, U.S. Naval Ondnance Iaboratory White Oak, (1971-1973). 
(14) Cowperthwaite, M. and Zwisler, W.H., "Improvement and Modification to the TIGER Code," (prepared for Naval Ordnance Laboratory White Oak under contract N60921-72-C-0013), Stanford Research Institute Project PYU-1397, January 1973.

(15) Cowperthwaite, M. and Zwisler, W.H. "TIGER Computer Program Documentation," (prepared for Lawrence Livenmore Laboratory under contract AT (04-3)-115, Naval Ordance Laboratory under contract N60921-72-C0013 and U.S. Anmy Picatinny Arsenal under contract DAAA21-71-C-0454), Stanford Research Institute Projects PYU-1281, PYU-1397, and PYU-1182, SRI Publication No. Z106, January 1973.

(16) (a) Kamlet, M.J. and Jacobs, S.J., J. Chem. Phys., 48, 23 (1968);

(b) Kamlet, M.J. and Ablard, J.E., J. Chen. Phys., 48, 36 (1968);

(c) Kamlet, M.J. and Dickinson, C., J. Chem. Phys., 48, 43 (1968);

(d) Kamiet, M.J. and Hurwitz, H., J. Chem. Phys., 48, 3685 (1968).

(17) Bernand, M.-L. Autard, P., Thomas, G., Le Gall, P., and Teyssendier de la Serve, J., C. R. Acad. Sc. Paris, 277, Série C-671 (1973).

(18) Ornellas, D.L., J. Phys. Chem., 72, 2390 (1968).

(19) Ornellas, D.L., Combustion and Flame, 23, 37 (1974).

(20) Ornellas, D.L., Carpenter, J.H., and Gunn, S.R., Rev of Scientific Instruments, 37, 907 (1966).

(21) McGuire, R.R. and Ornellas, D.L., "An Investigation of Chapman-Jougruet Detonation Theory Using Isotopic Labelling," Frank J. Seiler Research Laboratory Technical Report No. SRL-TR-75-0004 (April 1975).

Gibson, F.C., Bowser, M.L., Summers, C.R., Scott, F.H., and Mason, C.M.. J. Applied Phys., 29, 628 (1958).

Finger, M., Lee, E., Helm, F.H., Hayes, B., Hornig, H., MoGire, R. , Kahara, M., and Guidry, M., Lawrence Livemore Laboratory Report No. UCRL-78243, 24 May 1976. Proceedings of the Sixth Symposium (International) on Detonation (1976).

Dapoigny, J., Kieffer, J., and Vodar, B., J. de Physique et le Radium, 16. 733 (1955).

Christian, R.H. and Yanger, F.L., J. Chem. Phys., 23, 2042 (1955).

van Thiel, M. and Alder, J., J. Chem. Phys., 44, 1056 (1966).

Dick, R.D., Warnes, R.H., and Skalyo, J., Jr., J. Chem. Phys., 53,

1648 (1970). 
(28) Lagus, P.L. and Ahrens, T.J., J. Chem. Phys., 59, 3517 (1973).

(29) Walsh, J.M. and Rice, M.H., J. Chem. Phys., 26, 815 (1957).

(30) Zubarev, V.N. and Telegin, G.S., Soviet Physics-Doklady, I, 34 (1962).

(31) Dick, R.D., J. Chem. Phys., 52, 6021 (1970).

(32) Dapoigny, J., Kieffer, J. and Vodar, B., J. de Physique et le Radium, 17,606 (1956).

(33) van Thiel, M. and Alder, B.J., Molecular Phys., 10, 427 (1966).

(34) Grigor'ev, F.V. Kormer, S.B., Mikhailova, O.L., Tolochko, A.P., and Urlin, V.D., Sov. Phys-JEIP Letters, 16, 201 (1972).

(35) van Thiel, M., Ross, M., Hord, B.L., Mitchell, A.C., Gyst, W.H., D'Addario, M.J., and Keeler, R.N., Phys. Rev. Lett., 31, 979 (1973).

(36) Hirschfelder, J.O., Curtiss, C.F., and Bird, R.B., Molecular Theory of Gases and Liquids (Wiley, New York), 1954.

(37) Gray, D.E. (ed.) American Institute of Physics Handbook (McGraw-Hill, New York), 1963. p. 2-224.

(38) Bevington, Philip R., Data Reduction and Error Analysis for the Physical Sciences (McGraw-Hill, New York), 1969. pp. 237-240. 